\title{
Crescimento e acúmulo de íons em plantas de cajueiro anão precoce em diferentes tempos de exposição à salinidade
}

\section{Growth and ion accumulation in dwarf cashew plants at different times of salinity exposure}

\author{
Valdineia Soares Freitas ${ }^{1,2}$; Elton Camelo Marques²; Marlos Alves Bezerra3; \\ José Tarquinio Prisco ${ }^{4}$; Enéas Gomes-Filho ${ }^{4 *}$
}

\begin{abstract}
Resumo
O objetivo deste trabalho foi avaliar a influência da duração do estresse salino no crescimento e no acúmulo de íons em plantas jovens de cajueiro anão precoce. Para isso, castanhas do clone CCP 06 foram semeadas em bandejas plásticas contendo vermiculita umedecida com solução nutritiva adicionada de $\mathrm{NaCl}$, com condutividade elétrica variando entre 0,0 e 18,0 dS m${ }^{-1}$. Após 30 e 60 dias sob estresse, as plantas foram coletadas. Determinaram-se as massas secas da parte aérea (MSPA) e da raiz (MSR), a relação MSPA/MSR, os teores dos íons $\mathrm{Na}^{+}, \mathrm{K}^{+}, \mathrm{Cl}^{-}$e $\mathrm{NO}_{3}^{-}$e o fluxo dos íons $\mathrm{Na}^{+}$e $\mathrm{Cl}^{-}$para a planta inteira, entre os dois tempos de estresse analisados. $\mathrm{O}$ crescimento das plantas de cajueiro foi afetado pela salinidade e pelo tempo de exposição ao estresse, e as plantas submetidas a 60 dias de estresse foram as mais afetadas. Em todas as partes das plantas, os teores de $\mathrm{Na}^{+}$e $\mathrm{Cl}^{-}$foram aumentados enquanto os teores de $\mathrm{NO}_{3}^{-}$foram reduzidos e os de $\mathrm{K}^{+}$permaneceram inalterados. O fluxo dos íons $\mathrm{Na}^{+}$e $\mathrm{Cl}^{-}$para a planta inteira também aumentou com a salinidade, e o $\mathrm{Cl}^{-}$pareceu ter sido o íon mais prejudicial às plantas, uma vez que ele foi absorvido em uma proporção maior que o $\mathrm{Na}^{+}$. A redução do crescimento de cajueiro anão precoce é intensificada quando a exposição ao estresse salino é mais prolongada e está mais associada à absorção e ao acúmulo excessivo de $\mathrm{Cl}^{-}$do que de $\mathrm{Na}^{+}$.
\end{abstract}

Palavras-chave: Anacardium occidentale, estresse salino, fluxo de íons, solutos inorgânicos

\begin{abstract}
This work aimed to evaluate the influence of salt stress exposition on growth and ion accumulation in dwarf cashew plants. For this purpose, cashew nuts (CCP 06 clone) were sown in plastic trays containing vermiculite moistened with nutrient solution containing $\mathrm{NaCl}$ with electrical conductivities ranging from 0.0 to $18.0 \mathrm{dS} \mathrm{m}^{-1}$. Plants were harvested after 30 and 60 days under salt stress. It was determined the shoot dry masses (SDM) and root (RDM), the SDM/RDM ratio, $\mathrm{Na}^{+}, \mathrm{K}^{+}, \mathrm{Cl}^{-}$and $\mathrm{NO}_{3}^{-}$contents and the $\mathrm{Na}^{+}$and $\mathrm{Cl}^{-}$fluxes for whole plant in the period between two times of exposure to salt stress. The cashew growth was affected by salinity and by the exposure time to this stress, and the plants subjected to 60 days of stress were the most affected by $\mathrm{NaCl}$. The $\mathrm{Na}^{+}$and $\mathrm{Cl}^{-}$contents increased in all plant tissues, while the $\mathrm{NO}_{3}^{-}$content was reduced and $\mathrm{K}^{+}$content has not changed by salinity. The $\mathrm{Na}^{+}$and $\mathrm{Cl}^{-}$
\end{abstract}

${ }^{1}$ Prof $^{a}$ do Curso de Ciências Biológicas, Instituto Federal de Educação, Ciência e Tecnologia do Ceará, IFCE, Jaguaribe, CE. E-mail: valdineiasoares@ifce.edu.br

2 Discente de Doutorado do Programa de Pós-Graduação em Bioquímica, Universidade Federal do Ceará, UFC, Fortaleza, CE. E-mail: eltoncmarques@gmail.com

${ }^{3}$ Pesquisador da Embrapa Agroindústria Tropical e do Instituto Nacional de Ciência e Tecnologia em Salinidade, INCTSal/CNPq, Fortaleza, CE. E-mail: marlos.bezerra@embrapa.br

${ }^{4}$ Profs. do Dept ${ }^{\mathrm{o}}$ de Bioquímica e Biologia Molecular, Universidade Federal do Ceará, UFC, Pesquisador do Instituto Nacional de Ciência e Tecnologia em Salinidade, INCTSal/CNPq, Fortaleza, CE. E-mail: jtprisco@uol.com.br; egomesf@ufc.br

* Autor para correspondência 
fluxes increased with salinity; however $\mathrm{Cl}^{-}$seemed to be more harmful to plants, since this ion has been absorbed in a higher ratio than $\mathrm{Na}^{+}$. The growth reduction in dwarf cashew is intensified when exposure to salt stress is longer and it is more associated with uptake and excessive accumulation of $\mathrm{Cl}^{-}$than $\mathrm{Na}^{+}$.

Key words: Anacardium occidentale, salt stress, ion fluxes, inorganic solutes

\section{Introdução}

Em qualquer lugar onde cresçam, as plantas estarão sujeitas a condições de estresses múltiplos, que, por sua vez, poderão limitar seu crescimento e desenvolvimento (ASHRAF, 2009). Dentre os inúmeros estresses abióticos aos quais as plantas estão constantemente expostas, o estresse salino é um dos que mais comprometem o crescimento e a produtividade das plantas em todo o mundo (VEERANAGAMALLAIAH et al., 2007; ASHRAF, 2009).

O estresse salino é constituído de dois componentes: o osmótico e o iônico. O primeiro deles é decorrente da alta concentração de sais no ambiente radicular, que provoca a diminuição do potencial hídrico do solo e reduz a disponibilidade de água para a planta. Já o componente iônico decorre do acúmulo de certos íons (em geral, $\mathrm{Na}^{+} \mathrm{e} \mathrm{Cl}^{-}$) e pode provocar desequilíbrio nutricional, toxidez ou ambos (MUNNS, 2005; MUNNS; TESTER, 2008). Além disso, quanto maior o tempo de exposição ao estresse, mais complexos serão os distúrbios provocados por ele e menores serão as chances de recuperação das plantas (LARCHER, 2000).

As plantas desenvolveram mecanismos para prevenir e aliviar os danos provocados pelo excesso de sais, a fim de restabelecer suas condições homeostáticas e se aclimatar ao novo ambiente, retomando seu crescimento, ainda que a taxas reduzidas (BARTELS; SUNKAR, 2005). De modo geral, a tolerância das plantas à salinidade depende do controle do transporte dos sais, através de pelo menos um dos cinco mecanismos seguintes: i) seletividade no processo de absorção pelas células das raízes; ii) carregamento do xilema com $\mathrm{K}^{+}$em detrimento do $\mathrm{Na}^{+}$; iii) minimização da translocação dos íons $\mathrm{Na}^{+}$e $\mathrm{Cl}^{-}$para a parte aérea em crescimento; iv) compartimentação de sais em excesso no vacúolo; v) excreção de sais por estruturas especializadas. A tolerância em glicófitas depende dos três primeiros mecanismos, os quais ocorrem em diferentes graus, variando conforme a espécie e/ou cultivar (MUNNS et al., 2002).

A cajucultura é uma das principais atividades socioeconômicas da região Nordeste do Brasil, a qual é responsável por quase toda a produção brasileira de castanha, tendo destaque o estado do Ceará, que na safra de 2012, foi o responsável por mais de 59\% da produção nacional (IBGE, 2013). Nos últimos anos, algumas pesquisas foram realizadas com a finalidade de entender os efeitos do estresse salino no crescimento e no metabolismo de cajueiro anão precoce (ABREU et al., 2008; ALVAREZ-PIZARRO et al., 2009; MARQUES et al., 2011; MARQUES et al., 2013). Contudo, nessa espécie, estudos que relacionem as respostas das plantas à salinidade e o tempo de exposição a esse estresse são escassos. Baseado nisso, pretendeu-se estudar a influência da duração do estresse salino nos parâmetros de crescimento e no acúmulo de solutos inorgânicos em plantas de cajueiro anão precoce.

\section{Material e Métodos}

Castanhas de cajueiro anão precoce (Anacardium occidentale L.) pertencentes ao clone CCP 06, obtidas da EMBRAPA Agroindústria Tropical, foram selecionadas e tratadas com o fungicida tiofanato-metílico [Metiltiofan ${ }^{\circledR}$ (Uberaba, Minas Gerais, Brasil)] a 0,09\%, por 10 min e, em seguida, exaustivamente lavadas com água destilada, a fim de eliminar os resíduos do fungicida.

A semeadura foi realizada em bandejas de plástico contendo vermiculita umedecida, na proporção de 2:1 (v/v), com solução nutritiva de 
Clark (tratamento controle) ou com solução nutritiva de Clark adicionada de $\mathrm{NaCl}$, com condutividade elétrica (CE) de 3,$0 ; 6,0 ; 9,0 ; 12,0 ; 15,0$ ou 18,0 $\mathrm{dS} \mathrm{m}^{-1}$ (tratamentos salinos). No dia inicial do experimento, cada bandeja, contendo 16 castanhas, teve sua massa anotada, para que a água perdida por evapotranspiração fosse reposta diariamente. $\mathrm{O}$ experimento foi conduzido em casa de vegetação do Departamento de Bioquímica e Biologia Molecular da Universidade Federal do Ceará, Fortaleza, Ceará, Brasil (latitude $3^{\circ} 44^{\prime} \mathrm{S}$, longitude $38^{\circ} 34^{\prime}$ W), onde os valores médios de temperatura diurna e noturna e da umidade relativa do ar durante esse período foram, respectivamente, $31,1 \pm 1,5{ }^{\circ} \mathrm{C}, 27,4 \pm 1,1$ ${ }^{\circ} \mathrm{C}$ e $65,5 \pm 1,98 \%$.

As plantas foram coletadas aos 30 e 60 dias após a semeadura, sendo divididas em folhas, caules e raízes. Nessa ocasião, determinou-se a área foliar (AF) com o auxílio de um medidor de área foliar LiCor $^{\circledR}$, modelo LI-3100 (Lincoln, Nebraska, USA). O material coletado foi em seguida congelado e liofilizado. Após a liofilização, foram determinadas a massa seca da parte aérea (MSPA) e das raízes (MSR) e a relação MSPA/MSR.

$\mathrm{O}$ extrato utilizado para a determinação dos teores de $\mathrm{Na}^{+}, \mathrm{K}^{+}, \mathrm{Cl}^{-}$e $\mathrm{NO}_{3}^{-}$nas diferentes partes da planta foi preparado a partir da adição de $10 \mathrm{~mL}$ de água deionizada a $100 \mathrm{mg}$ do pó liofilizado, em tubos de ensaio, mantidos em banho-maria a $45{ }^{\circ} \mathrm{C}$, por $1 \mathrm{~h}$, com agitações a cada $15 \mathrm{~min}$. Decorrido esse tempo, os tubos foram centrifugados a $3.000 \mathrm{~g}$, por $15 \mathrm{~min}$, à temperatura ambiente. O sobrenadante foi filtrado em papel de filtro e armazenado a $-25^{\circ} \mathrm{C}$ até sua utilização, sendo o precipitado descartado. Os teores de $\mathrm{Na}^{+}$e $\mathrm{K}^{+}$foram determinados por fotometria de chama, os teores de $\mathrm{Cl}^{-}$, de acordo com Gaines, Parker e Gascho (1984), e os teores de
$\mathrm{NO}_{3}^{-}$, de acordo com Cataldo et al. (1975). De posse dos valores dos teores de $\mathrm{Na}^{+}$e $\mathrm{Cl}^{-}$, calculou-se o fluxo de absorção desses íons $\left(\mathrm{J}_{\mathrm{Na}}\right.$ e $\left.\mathrm{J}_{\mathrm{Cl}}\right)$ para a planta inteira, entre os dois tempos de estresse avaliados, conforme a equação abaixo:

$$
J_{\text {ion }}=\left[\left(\frac{M_{60}-M_{30}}{t_{60}-t_{30}}\right) \ln \left(\frac{\mathrm{MST}_{60} / \mathrm{MST}_{30}}{\mathrm{MST}_{60}-\mathrm{MST}_{30}}\right)\right]
$$

em que $\mathrm{M}$ é o teor de $\mathrm{Na}^{+}$ou $\mathrm{Cl}^{-}$na planta inteira, MST é a massa seca total da planta, e $\left(\mathrm{t}_{60}-\mathrm{t}_{30}\right)$ é o intervalo de tempo adotado (TATTINI; GUCCI, 1999).

O delineamento experimental foi o inteiramente casualizado, em arranjo fatorial $2 \times 7$ (dois tempos de estresse e sete níveis de salinidade), com cinco repetições. Os resultados obtidos foram submetidos à análise de variância (teste $F$ de Snedecor) e de regressão polinomial, cuja escolha do modelo baseou-se na significância dos coeficientes de regressão (teste $t$ de Student), associada ao maior valor do coeficiente de determinação $\left(\mathrm{R}^{2}\right)$.

\section{Resultados e Discussão}

O crescimento das plantas de cajueiro anão precoce foi significativamente $(p<0,001)$ afetado pela salinidade e pelo tempo de exposição a esse estresse (Tabela 1). A AF, a MSPA e a MSR foram reduzidas com o aumento da salinidade, sendo os maiores valores dessas variáveis observados após 60 dias de estresse (Figura 1). Os efeitos da salinidade sobre a AF, a MSPA e a MSR dependeram do tempo de duração do estresse, visto que apenas nessas variáveis é que houve interação significativa $(p<$ $0,001)$ entre tais fatores (Tabela 1). 
Tabela 1. Valores do teste $F$ de Snedecor para a área foliar (AF), massa seca da parte aérea (MSPA) e das raízes (MSR) e relação MSPA/MSR de plantas de cajueiro anão precoce em função do tempo de exposição e da intensidade do estresse salino.

\begin{tabular}{lcccc}
\hline Fontes de variação & AF & MSPA & MSR & MSPA/MSR \\
\hline Tempo (T) & $1799,78^{* * *}$ & $1409,43^{* * *}$ & $405,72^{* * * *}$ & $82,836^{* * *}$ \\
Salinidade (S) & $65,77^{* * *}$ & $58,14^{* * *}$ & $9,40^{* * *}$ & $5,059^{* * *}$ \\
T x S & $13,34^{* * *}$ & $6,11^{* * *}$ & $7,03^{* * *}$ & $1,698^{\text {ns }}$ \\
\hline
\end{tabular}

${ }^{* * *} P \leq 0,001{ }^{\text {ns }}$ não significativo

Fonte: Elaboração dos autores.

Figura 1. Área foliar $(\mathrm{AF}-\mathrm{A})$, massa seca da parte aérea (MSPA - B) e das raízes (MSR - C) e relação MSPA/MSR (D) de plantas de cajueiro anão precoce em função do tempo de exposição e da intensidade do estresse salino.

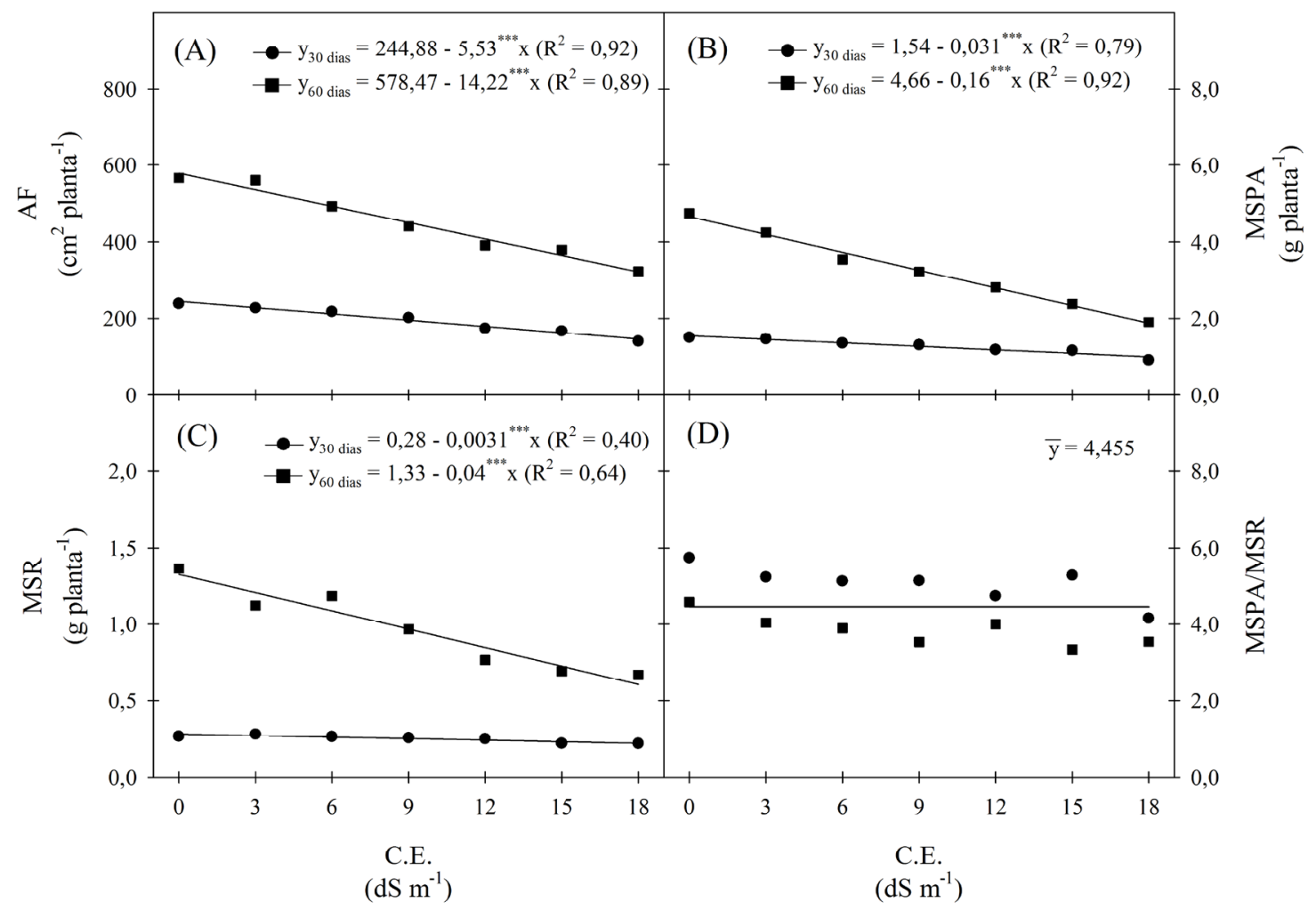

Fonte: Elaboração dos autores.

A AF das plantas de cajueiro anão precoce sob 30 ou 60 dias de estresse decresceu $2,26 \%$ e $2,46 \%$, respectivamente, para cada aumento unitário da $\mathrm{CE}$ da solução salina aplicada (Figura 1A). De acordo com Taiz e Zeiger (2013), os efeitos negativos da salinidade sobre a expansão foliar devem-se parcialmente ao aumento da pressão osmótica no meio radicular, ocasionado pelos sais. Isso contribui para a diminuição do potencial hídrico do solo e desfavorece a absorção de água pelas raízes das plantas, inibindo assim a atividade meristemática e o alongamento celular. Esses autores ressaltam que a expansão foliar também depende de fatores bioquímicos e moleculares. Dessa maneira, danos causados pelos sais às proteínas envolvidas nos processos de síntese de membranas e parede celular, 
bem como na divisão celular, podem também ter contribuído para os decréscimos de AF observados neste estudo. Além disso, em algumas plantas, o déficit hídrico ocasionado pela salinidade limita não apenas o tamanho, mas também o número de folhas, pois ele diminui a quantidade e a taxa de crescimento dos ramos (TAIZ; ZEIGER, 2013). Reduções na AF também foram observadas em outras espécies submetidas ao estresse salino, tais como algodão (FREITAS et al., 2011), feijão-decorda (LIMA et al., 2011), girassol (HEIDARI et al., 2011), milho (GOMES et al., 2011) e sorgo (FEIJÃO et al., 2011) e se constitui uma resposta típica das plantas, quando expostas à salinidade.

Um comportamento semelhante ao apresentado pela AF foi observado na MSPA e na MSR, que apresentaram, respectivamente, reduções de 2,01\% e $1,11 \%$, para as plantas sob 30 dias de estresse, e de $9,63 \%$ e 3,01\%, para as plantas sob 60 dias de estresse, para cada acréscimo unitário da CE (Figuras $1 \mathrm{~B}$ e 1C). Como se pode observar na Figura 1D, as reduções ligeiramente proporcionais na MSPA e na MSR das plantas de cajueiro anão precoce, causadas pela salinidade, refletiram-se na inalterabilidade da relação MSPA/MSR. De modo geral, as plantas sob 60 dias de estresse apresentaram as maiores reduções nos seus parâmetros de crescimento. É consenso entre diversos autores que a redução do crescimento das plantas em decorrência da salinidade ocorre em duas fases. A primeira delas diz respeito aos efeitos do componente osmótico, ocorrendo devido ao excesso de sais que se encontram na solução do solo, mostrando-se extremamente semelhante, do ponto de vista metabólico e celular, ao que ocorre em plantas sob estresse hídrico. Já a segunda, decorre do efeito direto dos sais, que ao serem absorvidos, acabam concentrando-se em quantidades superiores àquelas que as plantas são capazes de compartimentar em seus vacúolos, ficando dessa maneira dissolvidos no citosol e em outras organelas, onde acabam interferindo em inúmeras reações enzimáticas (MUNNS, 2005; MUNNS; TESTER, 2008).
Os teores de $\mathrm{Na}^{+}, \mathrm{Cl}^{-}$e $\mathrm{NO}_{3}{ }^{-}$nas diversas partes da planta foram afetados pela salinidade e pelo tempo de exposição ao estresse. Os teores de $\mathrm{K}^{+}$, por sua vez, variavam apenas em função do tempo em que as plantas estiveram sob estresse (Tabela 2). Ademais, a interação entre tempo e salinidade foi significativa apenas para os teores de $\mathrm{Cl}^{-}$, nas folhas, e de $\mathrm{Na}^{+}$e $\mathrm{Cl}^{-}$, nos caules (Tabela 2).

Os teores de $\mathrm{Na}^{+}$nas folhas (Figura $2 \mathrm{~A}$ ) e raízes (Figura 2E) aumentaram linearmente com os níveis crescentes de $\mathrm{NaCl}$ no meio de cultivo, alcançando valores máximos nas plantas submetidas a $\mathrm{CE}$ de $18 \mathrm{dS} \mathrm{m}^{-1}$. Esses aumentos foram similares, tanto para as plantas sob 30 dias quanto para aquelas sob 60 dias de estresse salino, embora essas últimas tenham apresentado os maiores teores de $\mathrm{Na}^{+}(P \leq$ 0,001) (Figuras 2A e 2E; Tabela 2). Já nos caules, as plantas sob 60 dias de estresse foram as que mais acumularam $\mathrm{Na}^{+}$(Figura 2C). Em glicófitas, os altos conteúdos de $\mathrm{Na}^{+}$nos tecidos é frequentemente considerado como um fator crítico causador de toxicidade (MUNNS, 2002; ZHU, 2007), já que conteúdos elevados de $\mathrm{Na}^{+}$nos tecidos vegetais, além de interferirem com a homeostase adequada do $\mathrm{K}^{+}$, também reduzem a disponibilidade, o transporte e a mobilização de $\mathrm{Ca}^{2+}$ para as regiões de crescimento, afetando assim os crescimentos vegetativo e reprodutivo das plantas (KADDOUR et al., 2012).

A salinidade não afetou significativamente os teores de $\mathrm{K}^{+}$nas diversas partes da planta e, de modo inverso ao observado com os teores $\mathrm{de}^{+}$, as plantas sob 60 dias de estresse apresentaram os menores teores desse íon em suas folhas, caule e raízes, em comparação às plantas sob 30 dias de estresse (Figuras 2B, 2D e 2F). Marques et al. (2011), ao estudar os efeitos da salinidade no desenvolvimento da plântula de cajueiro anão precoce, observaram que os teores de $\mathrm{K}^{+}$não se alteraram nos estádios de desenvolvimento correspondentes à germinação e à emergência da plântula, mas foram reduzidos no estádio de plântula estabelecida, sugerindo 
que a regulação dos teores de $\mathrm{K}^{+}$em condições salinas varia conforme o desenvolvimento da plântula e depende consequentemente da duração do estresse. Ferreira-Silva et al. (2008) também observaram redução nos teores de $\mathrm{K}^{+}$em raízes de plantas de cajueiro anão precoce submetidas à salinidade, e isso provavelmente ocorreu devido às altas concentrações de $\mathrm{NaCl}$ na solução de cultivo, que promoveram uma maior absorção de $\mathrm{Na}^{+}$, em detrimento da absorção de $\mathrm{K}^{+}$, seguida pelo vazamento de $\mathrm{K}^{+}$, como consequência do deslocamento de $\mathrm{Ca}^{2+}$ da superfície da raiz.
Segundo Lacerda (2005), o tempo de exposição ao estresse e a idade da folha são fatores que devem ser considerados quando se deseja analisar as respostas das plantas em relação ao acúmulo de $\mathrm{K}^{+}$, uma vez que ambos podem produzir diferentes resultados e interpretações. Em seus estudos, ele observou que plantas após seis dias de estresse mostraram reduções nos teores de $\mathrm{K}^{+}$, enquanto, aos 24 dias de estresse, houve um acúmulo desse íon em resposta à salinidade, levando a inferir que essas diferenças nos teores de $\mathrm{K}^{+}$estiveram relacionadas com a retranslocação desse íon, a qual foi mais intensa nas plantas controle.

Tabela 2. Valores do teste $F$ de Snedecor para os teores de $\mathrm{Na}^{+}, \mathrm{K}^{+}, \mathrm{Cl}^{-}$e $\mathrm{NO}_{3}^{-}$em folhas, caules e raízes de plantas de cajueiro anão precoce em função do tempo de exposição e da intensidade do estresse salino.

\begin{tabular}{ccccc}
\hline \multirow{2}{*}{ Fontes de variação } & $\mathrm{Na}^{+}$ & $\mathrm{K}^{+}$ & $\mathrm{Cl}^{-}$ & $\mathrm{NO}_{3}^{-}$ \\
\cline { 2 - 5 } & \multicolumn{3}{c}{ Folhas } \\
\hline Tempo (T) & $311,55^{* * *}$ & $516,31^{* * *}$ & $367,227^{* * *}$ & $286,97^{* * *}$ \\
Salinidade (S) & $115,15^{* * *}$ & $1,31^{\text {ns }}$ & $94,374^{* * *}$ & $30,01^{* * *}$ \\
T x S & $0,72^{\text {ns }}$ & $2,92^{\text {ns }}$ & $9,898^{* * *}$ & $2,29^{\text {ns }}$ \\
\hline \multicolumn{5}{c}{ Caules } \\
\hline Tempo (T) & $75,47^{* * *}$ & $171,37^{* * *}$ & $153,186^{* * *}$ & $24,314^{* * *}$ \\
Salinidade (S) & $38,02^{* * *}$ & $0,96^{\text {ns }}$ & $84,980^{* * *}$ & $3,703^{* *}$ \\
T x S & $5,29^{* * *}$ & $0,80^{\text {ns }}$ & $8,125^{* * *}$ & $5,195^{\text {ns }}$ \\
\hline & \multicolumn{5}{c}{ Raízes } \\
\hline Tempo (T) & $49,11^{* * *}$ & $198,58^{* * *}$ & $26,942^{* * *}$ & $114,883^{* * *}$ \\
Salinidade (S) & $86,94^{* * *}$ & $4,78^{\text {ns }}$ & $60,936^{* * *}$ & $9,203^{* * *}$ \\
T x S & $1,66^{\text {ns }}$ & $2,20^{\text {ns }}$ & $1,316^{\text {ns }}$ & $2,120^{\text {ns }}$ \\
\hline
\end{tabular}

${ }^{* *} P \leq 0,01 ;{ }^{* * *} P \leq 0,001$; ${ }^{\text {ns }}$ não significativo.

Fonte: Elaboração dos autores.

Semelhantemente ao $\mathrm{Na}^{+}$, os teores de $\mathrm{Cl}^{-}$nas folhas (Figura 3A), caules (Figura 3C) e raízes (Figura 3E) das plantas de cajueiro anão precoce aumentaram linearmente com os níveis crescentes de $\mathrm{NaCl}$ no meio de cultivo, em ambos os tempos de estresse, contudo esses aumentos dependeram do tempo de exposição à salinidade somente nas folhas e nos caules das plantas. Após 30 e 60 dias sob estresse salino, os teores de $\mathrm{Cl}^{-}$nas folhas aumentaram $13,15 \%$ e $13,98 \%$, respectivamente, para cada aumento unitário da CE no meio de crescimento, enquanto isso, nos caules, eles aumentaram 18,45\% e 23,38\%, respectivamente (Figuras 3A, 3C e 3E). Ferreira-Silva et al. (2008) também observaram que o íon $\mathrm{Cl}^{-}$acumula-se em maior quantidade nas folhas, quando comparado com o $\mathrm{Na}^{+}$, o que pode sugerir o papel relevante desempenhado por esse íon nos efeitos negativos do $\mathrm{NaCl}$ em plantas de cajueiro anão precoce. 
Figura 2. Teores de $\mathrm{Na}^{+}$e $\mathrm{K}^{+}$em folhas (A e B), caules (C e D) e raízes (E e F) de plantas de cajueiro anão precoce em função do tempo de exposição e da intensidade do estresse salino.

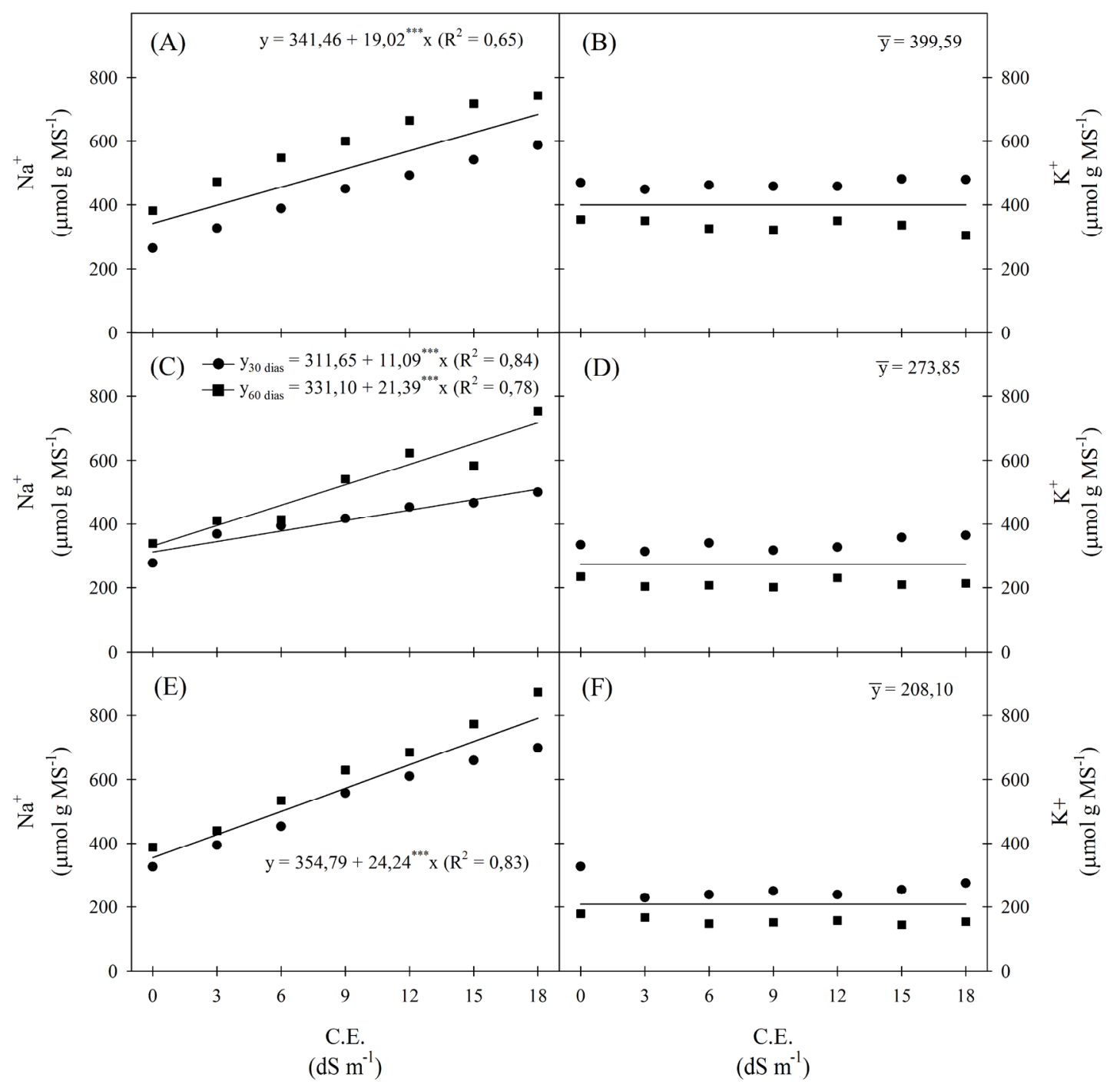

Fonte: Elaboração dos autores.

$\mathrm{O}$ estresse salino reduziu os teores de $\mathrm{NO}_{3}^{-}$ nas folhas e raízes $(2,35 \%$ e $1,89 \%$, em média, respectivamente, a cada aumento unitário da $\mathrm{CE}$ ) das plantas de cajueiro anão precoce, sendo que esse decréscimo não dependeu do tempo pelo qual elas estiveram sob estresse (Figuras 3B e 3F). Já os teores de $\mathrm{NO}_{3}^{-}$nos caules não foram afetados pela salinidade, tanto para as plantas sob 30 dias de estresse, quanto para as sob 60 dias (Figura 3D). Resultados semelhantes foram encontrados por Meloni et al. (2004), que observaram reduções nos teores de $\mathrm{NO}_{3}{ }^{-}$em folhas e raízes de plantas de algaroba sob condições de estresse salino.

As plantas requerem nitrogênio em altas concentrações e sua deficiência inibe rapidamente o crescimento e, consequentemente, sua produção (TAIZ; ZEIGER, 2013; MAATHUIS; DIATLOFF, 2012). Neste trabalho, as reduções no crescimento observadas nas plantas de cajueiro anão precoce podem estar relacionadas ao fato de a salinidade interferir no metabolismo do nitrogênio, que é 
um dos elementos essenciais à planta, estando envolvido no crescimento e no desenvolvimento vegetal e participando na constituição de muitas biomoléculas, tais como proteínas, ácidos nucleicos, aminoácidos, coenzimas, vitaminas e pigmentos (TAIZ; ZEIGER, 2013; MAATHUIS; DIATLOFF, 2012). Feijão et al. (2011), estudando o efeito de duas concentrações de $\mathrm{NO}_{3}^{-}(0,5$ e $8,0 \mathrm{mM}$ de nitrato) em plantas de sorgo sudão sob condições de salinidade, observaram que o aumento do suprimento de $\mathrm{N}$ foi capaz de promover o crescimento das plantas de sorgo sudão, tanto em condições controle quanto de salinidade. Isso se deveu, pelo menos em parte, aos maiores valores dos parâmetros de trocas gasosas (fotossíntese líquida, transpiração, condutância estomática e relação entre a concentração interna e externa de $\mathrm{CO}_{2}$ ) e à redução da translocação de íons $\mathrm{Na}^{+}$e $\mathrm{Cl}^{-}$para as folhas, resultando em um melhor crescimento nas plantas nutridas com $\mathrm{NO}_{3}^{-}$a 8,0 $\mathrm{mM}$, em comparação com plantas nutridas com $0,5 \mathrm{mM}$, ressaltando a importância da manutenção adequada das concentrações de $\mathrm{N}$ em plantas sob condições de salinidade.

Figura 3. Teores de $\mathrm{Cl}^{-}$e $\mathrm{NO}_{3}{ }^{-}$em folhas (A e B), caules (C e D) e raízes (E e F) de plantas de cajueiro anão precoce em função do tempo de exposição e da intensidade do estresse salino.

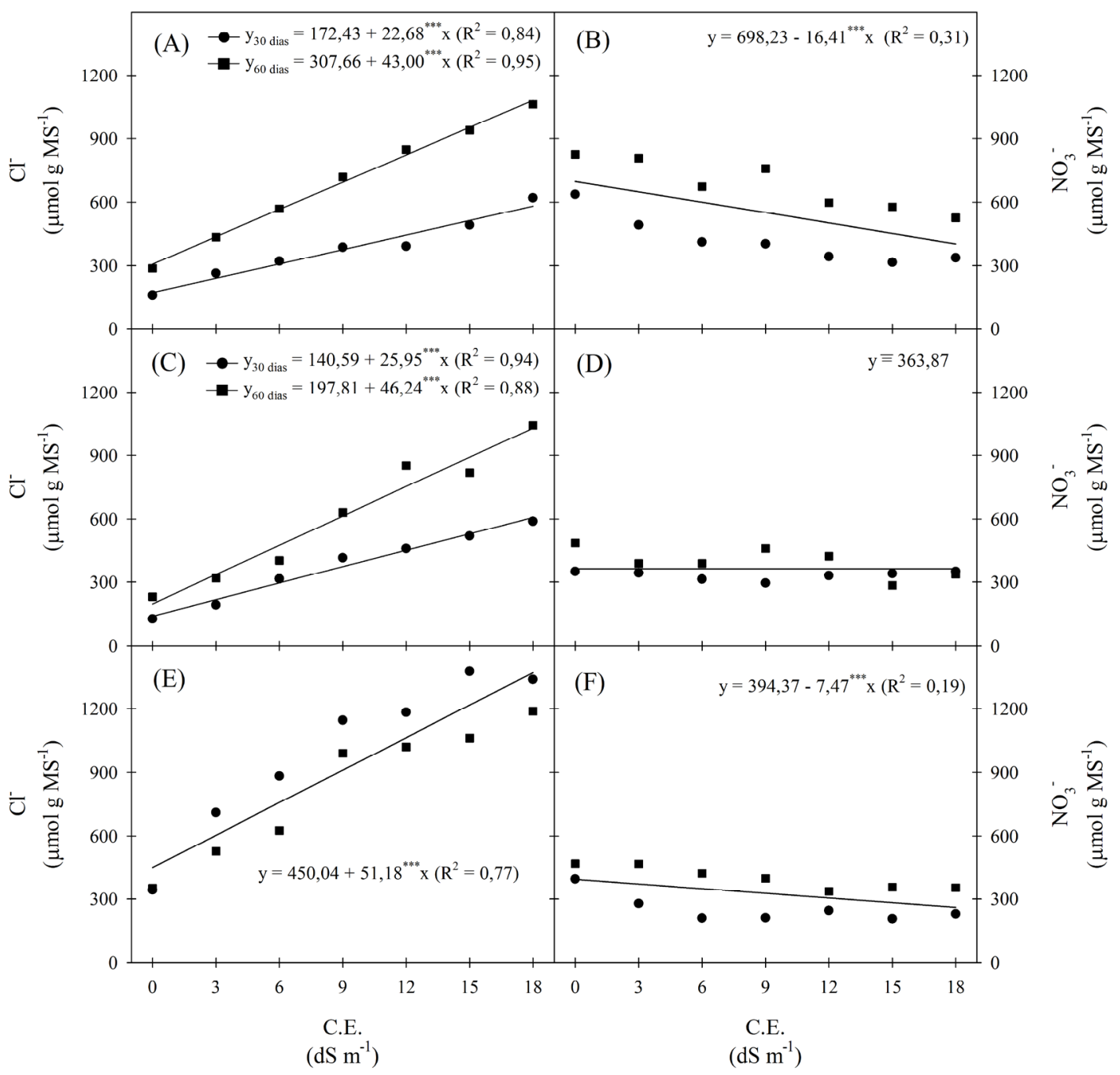

Fonte: Elaboração dos autores. 
Comparando-se os teores dos íons tóxicos $\left(\mathrm{Na}^{+}\right.$ e $\mathrm{Cl}^{-}$) dos três órgãos da planta estudados, observase que a maior parte deles foi acumulada nas raízes (Figuras 2 e 3). A habilidade das plantas em limitar a absorção e transporte de íons da zona radicular para a parte aérea, evitando assim o seu acúmulo em níveis que excedam a capacidade das células em compartimentá-los no vacúolo, constitui-se um mecanismo de tolerância à salinidade em glicófitas (MUNNS, 2005; MUNNS; TESTER, 2008).

Para tentar estabelecer uma correlação entre o acúmulo de íons tóxicos e o agravamento dos efeitos da salinidade nas plantas sob 60 dias de estresse, procedeu-se ao cálculo do fluxo de absorção de $\mathrm{Na}^{+}$ e $\mathrm{Cl}^{-}$(para a planta inteira). Os fluxos de ambos os íons aumentaram consideravelmente com a salinidade, entretanto o $\mathrm{Cl}^{-}$parece ter sido o mais prejudicial às plantas, uma vez que esse íon foi absorvido em uma maior proporção do que o $\mathrm{Na}^{+}$ (Figura 4). O aumento da CE do meio de cultivo (de 0,0 a $18,0 \mathrm{dS} \mathrm{m}^{-1}$ ) foi acompanhado por um acréscimo de $185 \%$, no fluxo de absorção de $\mathrm{Na}^{+}$, e de $513 \%$, no de $\mathrm{Cl}^{-}$(Figura 4 ).

Figura 4. Transporte dos íons $\mathrm{Na}^{+}(\boldsymbol{\Delta})$ e $\mathrm{Cl}^{-}(\boldsymbol{\nabla})$ para a planta inteira, em cajueiro anão precoce em função do tempo de exposição e da intensidade do estresse salino. As medidas foram realizadas no período final do estresse salino (60 dias após a semeadura) utilizando-se 5 plantas para cada tratamento salino.

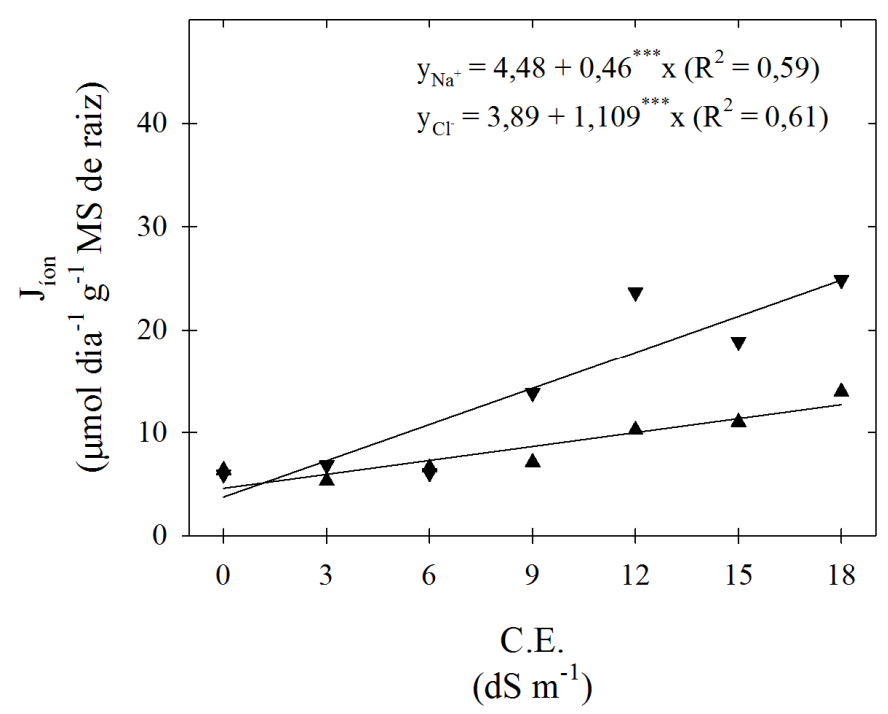

Fonte: Elaboração dos autores.

A tolerância das plantas à salinidade requer, dentre vários fatores, a compartimentação de íons $\mathrm{Na}^{+}$e $\mathrm{Cl}^{-}$nos tecidos, a níveis intra/extracelular, a fim de evitar concentrações tóxicas dentro do citoplasma, especialmente nas células do mesofilo foliar (ZHANG et al., 2011). Na maioria das culturas, tais como algodão, feijão, trigo e arroz, o $\mathrm{Na}^{+}$parece contribuir mais do que o $\mathrm{Cl}^{-}$para a toxidez em plantas sob estresse salino. Contudo, existem estudos que demonstram que algumas culturas (soja e citros, por exemplo) são mais sensíveis ao $\mathrm{Cl}^{-}$do que ao $\mathrm{Na}^{+}$(BRUMÓS et al., 2009; LUO; YU; LIU, 2005; ZHANG et al., 2011).

Em um estudo realizado com cultivares e híbridos provenientes desses cultivares de soja tolerantes à salinidade, Zhang et al. (2011) observaram um maior aumento no influxo celular 
de $\mathrm{Cl}^{-}$e $\mathrm{Na}^{+}$nas raízes e folhas das plantas sensíveis com o prolongamento do tempo de estresse salino, enquanto que nas plantas tolerantes ocorreu um efluxo de $\mathrm{Na}^{+}$, associado a um menor influxo de $\mathrm{Cl}^{-}$. Para esses autores, as diferenças de tolerância à salinidade entre cultivares e híbridos de soja são atribuídas principalmente à capacidade da planta de restringir o acúmulo dos íons $\mathrm{Cl}^{-}$na parte aérea, especialmente nas folhas.

Com base nisso, sugere-se que os decréscimos nos parâmetros de crescimento das plantas de cajueiro anão precoce sob 60 dias de estresse estão mais relacionados à absorção e ao acúmulo excessivo de $\mathrm{Cl}^{-}$do que de $\mathrm{Na}^{+}$.

\section{Conclusões}

O crescimento das plantas de cajueiro anão precoce é reduzido à medida que o estresse salino intensifica-se, sendo esse efeito mais pronunciado quando o tempo de exposição é maior.

O agravamento da redução do crescimento está mais associado à absorção e ao acúmulo de $\mathrm{Cl}^{-}$do que de $\mathrm{Na}^{+}$.

\section{Agradecimentos}

Os autores agradecem ao Conselho Nacional de Desenvolvimento Científico e Tecnológico (CNPq), ao Instituto Nacional de Ciência e Tecnologia em Salinidade (INCTSal) e à Fundação Cearense de Apoio ao Desenvolvimento Científico e Tecnológico (FUNCAP), pela concessão de bolsas e recursos financeiros, indispensáveis à realização deste trabalho de pesquisa.

\section{Referências}

ABREU, C. E. B.; PRISCO, J. T.; NOGUEIRA, A. R. C.; BEZERRA, M. A.; LACERDA, C. F.; GOMES-FILHO, E. Physiological and biochemical changes occurring in dwarf-cashew seedlings subjected to salt stress. Brazilian Journal of Plant Physiology, Londrina, v. 20, n. 2, p. 105-118, 2008.
ALVAREZ-PIZARRO, J. C.; GOMES-FILHO, E.; LACERDA, C. F.; ALENCAR, N. L. M.; PRISCO, J. T. Salt-indu'ced changes on $\mathrm{H}^{+}$-ATPase activity, sterol and phospholipid content and lipid peroxidation of root plasma membrane from dwarf-cashew (Anacardium occidentale L.) seedlings. Plant Growth Regulation, Dordrescht, v. 59, n. 2, p. 125-135, 2009.

ASHRAF, M. Biotechnological approach of improving plant salt tolerance using antioxidants as markers. Biotechnology Advances, New York, v. 27, n. 1, p. 84-93, 2009.

BARTELS, D.; SUNKAR, R. Drought and salt tolerance in plants. Critical Reviews in Plant Sciences, Lagos, v. 24, n. 1, p. 23-58, 2005.

BRUMÓS, J.; COLMENERO-FLORES, J. M.; CONESA, A.; IZQUIERDO, P.; SÁNCHEZ, G.; IGLESIAS, D. J.; LÓPEZ-CLIMENT, M. F.; GÓMEZCADENAS, A.; TALÓN, M. Membrane transporters and carbon metabolism implicated in chloride homeostasis differentiate salt stress responses in tolerant and sensitive Citrus rootstocks. Functional \& Integrative Genomics, Berlin, v. 9, n. 3, p. 293-309, 2009.

CATALDO, D. A.; HAROON, M.; SCHRADER, L. E.; YOUNGS, V. L. Rapid colorimetric determination of nitrate in plant tissue by nitration of salicylic. Communications in Soil Science and Plant Analysis, New York, v. 6, n. 1, p. 71-80, 1975.

FEIJÃO, A. R.; SILVA, J. C. B.; MARQUES, E. C.; PRISCO, J. T.; GOMES-FILHO, E. Efeito da nutrição de nitrato na tolerância de sorgo sudão à salinidade. Revista Ciência Agronômica, Fortaleza, v. 42, n. 3, p. 675-683, 2011.

FERREIRA-SILVA, S. L.; SILVEIRA, J. A. G.; VOIGT, E. L.; SOARES, L. S. P.; VIÉGAS, R. A. Changes in physiological indicators associated with salt tolerance in two contrasting cashew rootstocks. Brazilian Journal of Plant Physiology, Londrina, v. 20, n. 1, p. 51-59, 2008.

FREITAS, V. S.; ALENCAR, N. L. M.; LACERDA, C. F.; PRISCO, J. T.; GOMES-FILHO, E. Changes in physiological and biochemical indicators associated with salt tolerance in cotton, sorghum and cowpea. African Journal Biochemistry Research, Durban, v. 5, n. 8, p. 264-271, 2011.

GAINES, T. P.; PARKER, M. B.; GASCHO, G. J. Automated determination of chlorides in soil and plant tissue by sodium nitrate. Agronomy Journal, Madison, v. 76, n. 3, p. 371-374, 1984.

GOMES, K. R.; AMORIM, A. V.; FERREIRA, F. J.; FILHO, F. L. A.; LACERDA, C. F.; GOMES-FILHO, E. Resposta de crescimento e fisiologia do milho submetido 
a estresse salino com diferentes espaçamentos de cultivo. Revista Brasileira de Engenharia Agrícola e Ambiental, Campina Grande, v. 15, n. 4, p. 365-370, 2011.

HEIDARI, A.; TOORCHI, M.; BANDEHAGH, A.; SHAKIBA, M-R. Effect of $\mathrm{NaCl}$ stress on growth, water relations, organic and inorganic osmolytes accumulation in sunflower (Helianthus annuus L.) lines. Universal Journal of Environmental Research and Technology, Katraj, v. 1, n. 3, p. 351-362, 2011.

INSTITUTO BRASILEIRO DE GEOGRAFIA E ESTATÍSTICA - IBGE. Indicadores IBGE: estatística da produção agrícola. 2013. Disponível em: <http://www. ibge.gov.br/home/estatistica/>. Acesso em: 10 abr. 2013.

KADDOUR, R.; MAHMOUDI, H.; BAÂTOUR, O.; TARCHOUN, I.; NASRI, N.; SALEH, I. B.; BERTHOMIEU, P.; GRUBER, M.; LACHAÂL, M. Physiological and molecular responses of two Arabidopsis accessions to calcium amendment and salt constraint. Acta Physiologiae Plantarum, Warsow, v. 34, n. 2, p. 439-450, 2012.

LACERDA, C. F. Interação salinidade $\mathrm{x}$ nutrição mineral. In: NOGUEIRA, R. J. M. C.; ARAÚJO, E. L.; WILLADINO, L. G.; CAVALCANTE, U. M. T. (Ed.). Estresses ambientais: danos e benefícios em plantas. Recife: UFRPE, 2005. p. 127-137.

LARCHER, W. Ecofisiologia vegetal. São Carlos: Rima Artes e Textos, 2000. $531 \mathrm{p}$.

LIMA, M. A.; CASTRO, V. F.; VIDAL, J. B.; ENÉASFILHO, J. Aplicação de silício em milho e feijão-decorda sob estresse salino. Revista Ciência Agronômica, Fortaleza, v. 42, n. 2, p. 398-403, 2011.

LUO, Q.; YU, B.; LIU, Y. Differential sensitivity to chloride and sodium ions in seedlings of Glycine max and G. soja under $\mathrm{NaCl}$ stress. Journal of Plant Physiology, Stuttgart, v. 162, n. 9, p. 1003-1012, 2005.

MAATHUIS, F. J.; DIATLOFF, E. Roles and functions of plant mineral nutrients. In: MAATHUIS, F. J. (Ed.). Plant mineral nutrients: methods and protocols. Totowa: Springer, 2012. p. 1-21.

MARQUES, E. C.; FREITAS, V. S.; BEZERRA, M. A.; PRISCO, J. T.; GOMES-FILHO, E. Efeitos do estresse salino na germinação, emergência e estabelecimento da plântula de cajueiro anão precoce. Revista Ciência Agronômica, Fortaleza, v. 42, n. 4, p. 993-999, 2011.

MARQUES, E. C.; FREITAS, P. A. F.; ALENCAR, N. L. M.; PRISCO, J. T.; GOMES-FILHO, E. Increased $\mathrm{Na}^{+}$and $\mathrm{Cl}^{-}$accumulation induced by $\mathrm{NaCl}$ salinity inhibits cotyledonary reserve mobilization and alters the source-sink relationship in establishing dwarf cashews seedlings. Acta Physiologiae Plantarum, Warsow, v. 35, n. 7, p. 2171-2182, 2013.

MELONI, D. A.; GULOTTA, M. R.; MARTÍNEZ, C. A.; OLIVA, M. A. The effects of salt stress on growth, nitrate reduction and proline and glycinebetaine accumulation in Prosopis alba. Brazilian Journal of Plant Physiology, Londrina, v. 16, n. 1, p. 39-46, 2004.

MUNNS, R. Comparative physiology of salt and water stress. Plant, Cell and Environment, Oxford, v. 25, n. 2, p. 239-250, 2002.

. Genes and salt tolerance: bringing them together. New Phytologist, Cambridge, v. 167, n. 3, p. 645-663, 2005.

MUNNS, R.; HUSAIN, S.; RIVELLI, A. R.; JAMES, R. A.; CONDON, A. G. T.; LINDSAY, M. P.; LAGUDAH, E. S.; SCHACHTMAN, D. P.; HARE, R. A. Avenues for increasing salt tolerance of crops, and the role of physiologically based selection traits. Plant and Soil, The Hague, v. 247, n. 1, p. 93-105, 2002.

MUNNS, R.; TESTER, M. Mechanisms of salinity tolerance. Annual Review of Plant Biology, Palo Alto, v. 59, n. 1, p. 651-681, 2008.

TAIZ, L.; ZEIGER, E. Fisiologia vegetal. 5. ed. Porto Alegre: Artmed, 2013. 918 p.

TATTINI, M.; GUCCI, R. Ionic relations of Phillyrea latifolia L. plants during $\mathrm{NaCl}$ stress and relief from stress. Canadian Journal of Botany, Ottawa, v. 77, n. 7, p. 969-975, 1999.

VEERANAGAMALLAIAH, G.; SIVAKUMAR, P.; CHAKRABARTY, R.; THOMAS, G. Glutamine synthetase expression and pyrroline-5-carboxylate reductase activity influence proline accumulation in two cultivars of foxtail millet (Setaria italica L.) with differential salt sensitivity. Environmental and Experimental Botany, Elmsford, v. 60, n. 2, p. 239-244, 2007.

ZHANG, X. K.; ZHOU, Q. H.; CAO, J. H.; YU, B. J. Differential $\mathrm{Cl}^{-} /$salt tolerance and $\mathrm{NaCl}$ - induced alterations of tissue and cellular ion fluxes in Glycine max, Glycine soja and their hybrid seedlings. Journal of Agronomy and Crop Science, Saskatoon, v. 197, n. 5, p. 329-339, 2011.

ZHU, J. K. Plant salt stress. Encyclopedia of life sciences. 2007. Disponível em: <http://dx.doi. org/10.1002/9780470015902.a0001300.pub2 >. Acesso em: 22 out. 2012. 
